\title{
Construction and optimization of a power complex with a distributed generation on the basis of renewables and methods of artificial intelligence (on the example of the Republic of Tajikistan)
}

\author{
Vadim Manusov ${ }^{1}$, Alifbek Kirgizov², and Javod Ahyoev ${ }^{1 \mathrm{a}}$ \\ ${ }^{1}$ Novosibirsk state technical university, 630073, Novosibirsk, Russia \\ ${ }^{2}$ Tajik technical university of a name of the academician M.S. Osimi, 734042, Dushanbe, Republic \\ of Tajikistan
}

\begin{abstract}
In this article the basic principles and classifications of small hydroelectric power stations depending on the power of system in which they work are provided. Especially, in the conditions of Tajikistan when all small hydroelectric power stations in some regions carry out the functions of big hydroelectric power stations. We suggest to use new classification by using function of fuzzy logic. The new concept of a power complex (HUB) on the basis of the renewed energy source (RES) is also offered.
\end{abstract}

\section{Introduction}

In recent years the agricultural enterprises and rural population of the Republic of Tajikistan has been facing constant deficiency of electric energy which is the main source for heating in households. Today this deficiency especially became aggravated and the population in the majority of rural areas receive the electric power during the winter time only few hours per day. It leads to unpleasant consequences in all spheres of life and agricultural activity of areas, namely: in economy, education, health care, the social sphere.

\section{Relevance}

Rural, especially remote and hard to access regions of the Republic of Tajikistan can be reliably provided with the electric power only due to construction of small hydroelectric power stations (MGES) or other renewables, such as wind turbines and solar batteries. Potential resources of a small-scale power generation of the Republic of Tajikistan in general are very great and significantly over exceeds the real demand, even with considering the perspective development of power engineering sphere in the long term future.

\footnotetext{
${ }^{\text {a }}$ Corresponding author: Javod 66@mail.ru
} 
The availability of water flow, temperature, and wind speed is required for the production of electricity, that is for determining the optimal installed capacity and an average annual energy production by small hydro power plants and wind power plants.

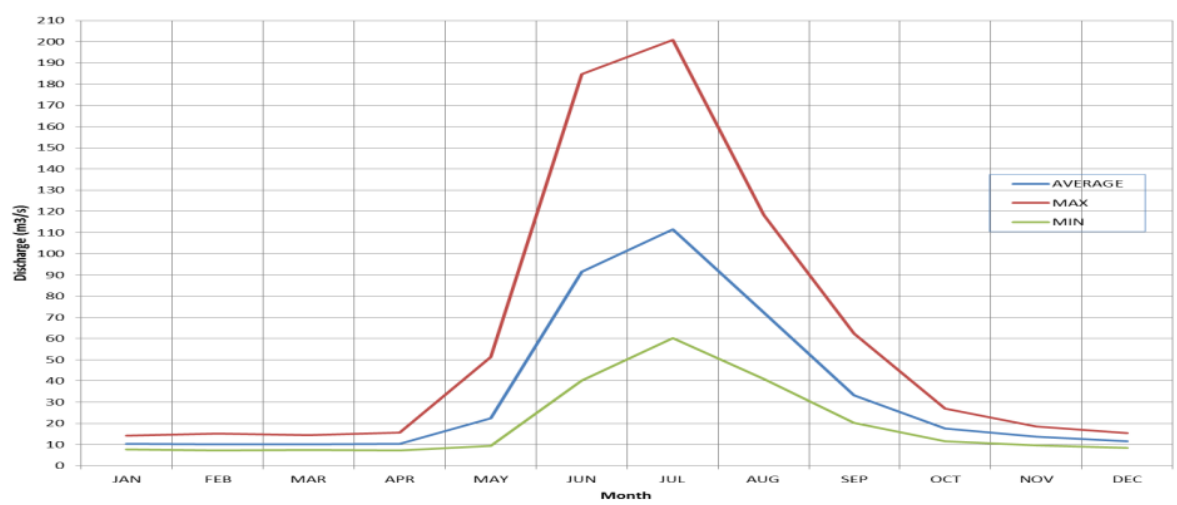

Fig. 1. A typical graph of the water regime changes in small water inflows of the Eastern Pamirs.

Average discharge highly varies from year to year, as shown in Figure 1, from $24 \mathrm{~m}^{3} / \mathrm{s}$ to $48 \mathrm{~m}^{3} / \mathrm{s}$ from average annual discharge of water.

Despite all this, progress in implementation of the program of development of the small-scale power distributed generation and construction of Small Hydro Power Stations (SHPS) in the Republic of Tajikistan is very modest. One of the main reasons for such slow development is lack of accurately developed strategy for development of the small distributed hydropower of the Republic and the main concept of development of a power complex which in literature is characterized now by the term HUB. HUB is a power knot (complex) which includes different types of power sources such as mineral raw materials, for example, coal, oil products, etc. HUB offered in this work represents composition of the distributed renewable sources of a net energy of different types, such as small hydroelectric power stations, low-power wind turbines, solar batteries and static stores of energy (BESS - Battery Energy Storage System). This is the fundamental difference of the offered HUB in the Republic of Tajikistan.

\section{Problem definition}

Currently, there is confusion in the concepts of small-scale power generation. Along with the term "small hydropower" also "nonconventional", "alternative" terms are used that creates confusion and difficulties in the use of world experience of the developed countries which have different condition in comparison to the Republic of Tajikistan.

First of all, it is required to concretize concept of small hydroelectric power station. Specification of classifications of Small Hydro Power Stations (SHPS) by power and local electric networks which will participate in work of HUB. Especially it concerns the region of Gorno Badakhshan Autonomous Oblast (GBAO) where all kind of basic hydroelectric power stations (both existing and planned), formally classified as "small", however carrying out actually the functions of "big" power station. It can create uncertainty in their status, ownership and the role of the state in their management.

Nowadays, not explicitly, but there is an understanding that small hydroelectric power stations, are those large hydroelectric power stations, but in a small size. Apparently, the division is necessary not only according to capacity, but also according to structure of consumers, operating mode, meeting the production schedule, construction and connecting consumers is necessary. It would be correct in order to define the limit 
of the SHPS capacities to link relative values of power to fixed capacity of the energy system to the extent of the development of the country and other factors. It would be necessary to connect limits of capacities of SHPS with development rate of the country, one of the indicators is the total capacity of a power supply system. The accepted classification parameters for big hydroelectric power stations and SHPS are almost identical, except the capacity limit which in the different countries is applied differently. It creates additional difficulty for definition of exact classification of SHPS especially in low-capacity systems. More exact and similar classification can be determined by function of belonging of station to small, as SHPS capacity is not fixed value, but intersected classes.

The histogram of distribution of the existing hydroelectric power stations by capacity is presented in figure 1, from total number of 325 hydroelectric power stations of the Republic of Tajikistan.

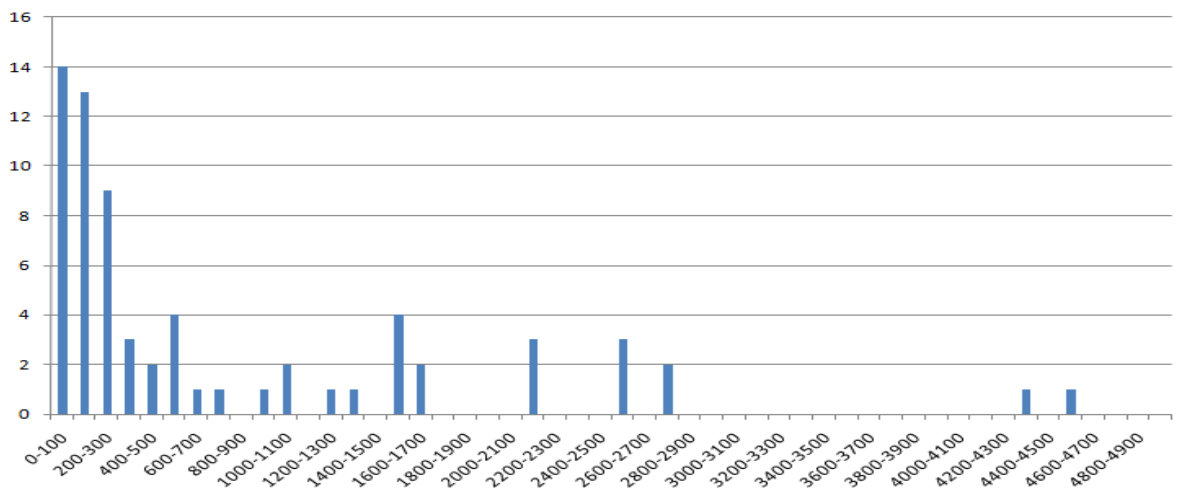

Fig. 2. Histogram of power -stations of Tajikistan by capacity.

Based on their functions of participation in the wholesale market of the electric power, hardware and types of management it is expedient to highlight the following groups of distributed generation of hydroelectric power station: micro hydroelectric power station, mini hydroelectric power station and small hydroelectric power stations. Since clear breakdown of hydroelectric power station by capacity depending on their quantity isn't possible, indistinct classification on the basis of functions of belonging of intersected classes is accepted which is presented in figure 2.

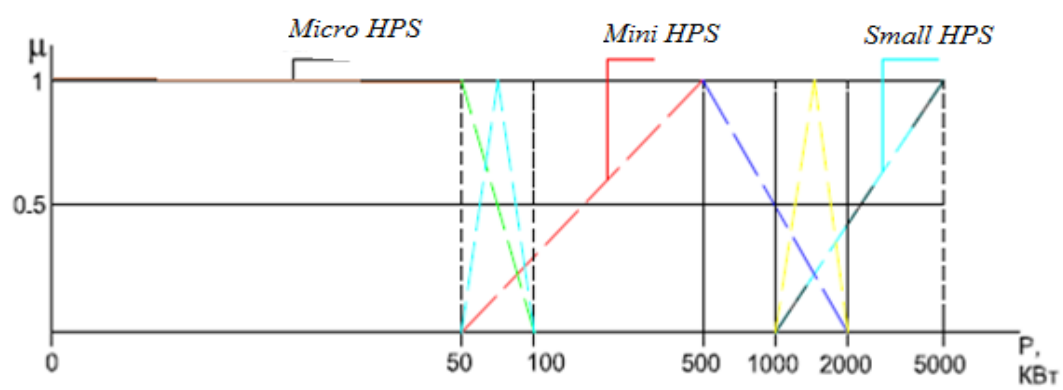

Fig. 3. Fuzzy classification of SHPS adapted to conditions in the Republic of Tajikistan.

In Figure 2 it is visible that micro hydroelectric power station includes stations from 0 to $50 \mathrm{~kW}$, the mini hydroelectric group includes stations with the capacity from 50 to 2000 $\mathrm{kW}$, and small hydroelectric power station includes the stations with the capacity from 1000 to $5000 \mathrm{KW}$. 
This classification ascribes some degree of overlap between micro and mini HPS in the range of 50 to $100 \mathrm{~kW}$ and a fuzzy zone between mini and small HPS in range of 1000 to $2000 \mathrm{~kW}$. Such a fuzzy classification is proposed for the first time and, evidently, it reflects the situation on the ground more realistically.

The mathematical expression for the functions of belonging in the general form of triangular L-R function is represented by the formula (1). For the classification of micro Hydro Power Plants (HPPs) the function of belonging is defined by the formula (2). For the classification of mini HPPs the function of belonging is defined by the formula (3). For the classification of small HPPs the function of belonging is defined by the formula (4)

$$
\begin{aligned}
& \mu\left(x_{i}\right),\left\{\begin{array}{c}
0 ., c_{i} \leq x \leq a_{i} \\
\frac{x-a_{i}}{b_{i}-a_{i}}, a_{i} \leq x \leq b_{i} \\
\frac{c_{i}-x}{c_{i}-b_{i}}, b_{i} \leq x \leq c_{i}
\end{array}\right. \\
& \mu\left(x_{i}\right),\left\{\begin{array}{c}
0 ., 0 \leq x \leq 50 \\
\frac{100-x}{c_{i}-50}, 50 \leq x \leq 100 \\
0,, 100 \leq x,
\end{array}\right. \\
& \mu\left(x_{i}\right),\left\{\begin{array}{c}
\frac{x-500}{500-50}, 50 \leq x \leq 500 \\
\frac{2000-x}{2000-500},, 500 \leq x \leq 2000
\end{array}\right. \\
& \mu\left(x_{i}\right),\left\{\begin{array}{c}
0 ., 1000 \leq x \\
\frac{x-1000}{5000-1000}, 1000 \leq x \leq 5000 \\
1,500 \leq x \leq 2000
\end{array}\right.
\end{aligned}
$$

Similar classification for the distributed generation can be executed for small mini and micro wind-power turbine in a class from 50 to $500 \mathrm{~kW}$.

As the main development energy in the Republic is the share of RES and depending on their unpredictability and unevenness of transition into daily mode, their connection to HUB is the most rational way of increasing their reliable functioning.

One way to use the existing infrastructures more effectively they need to be considered as one integrated system in planning and operation of energy. For this purpose, it is necessary to connect all sources to one center which, allows optimization of their work depending on requirements and availability of energy.

If infrastructures are integrated properly, energy can be exchanged among them, integrated, in particular during congestion it is possible to exercise their control. For example, in certain times the transmission lines of energy can be overloaded and transfer can be reduced, having moved part of power energy to another a network and moving it to less critical points in system. But it would demand the integration of appropriate tools of all energy carriers and their collaboration.

Consideration of multiple inputs, the power center (HUB) can be used to meet the demand for consumption of production and clearly this center usually increases availability of energy to consumers because it doesn't depend on only infrastructure any more. The outlined concept is presented in Figure 4. 


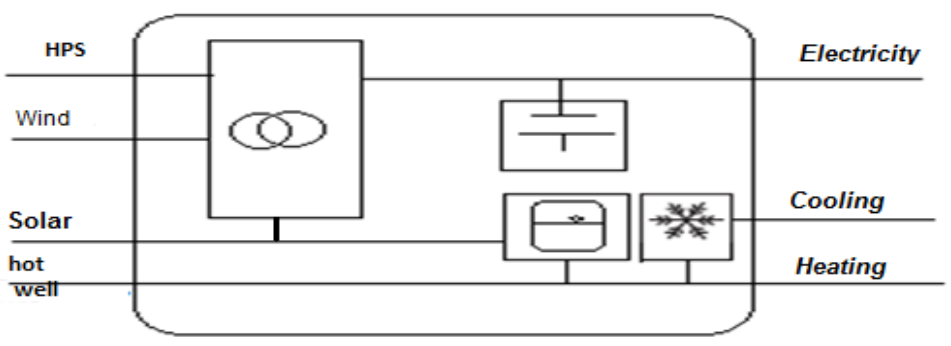

Fig. 4. Association of all sources in the uniform power center.

Along with hydropower resources in this work a study and evaluation of the energy potential of wind energy was conducted for different regions of the Republic of Tajikistan which is presented in Figure 5 with a buffer accumulation of energy. While assessing wind energy capacity in the cities of the Republic of Tajikistan, it was found out that the most common wind power units (WPU) are from 10 to $30 \mathrm{~kW}$, although in some cases up to $120 \mathrm{~kW}$. In accordance with the previously mentioned classification of the function of belonging the wind power units should be classified as micro stations (as defined by the formula (2). Therefore, the potential of wind energy is not very large, but it is useful for rural areas, as it is distributed generation.

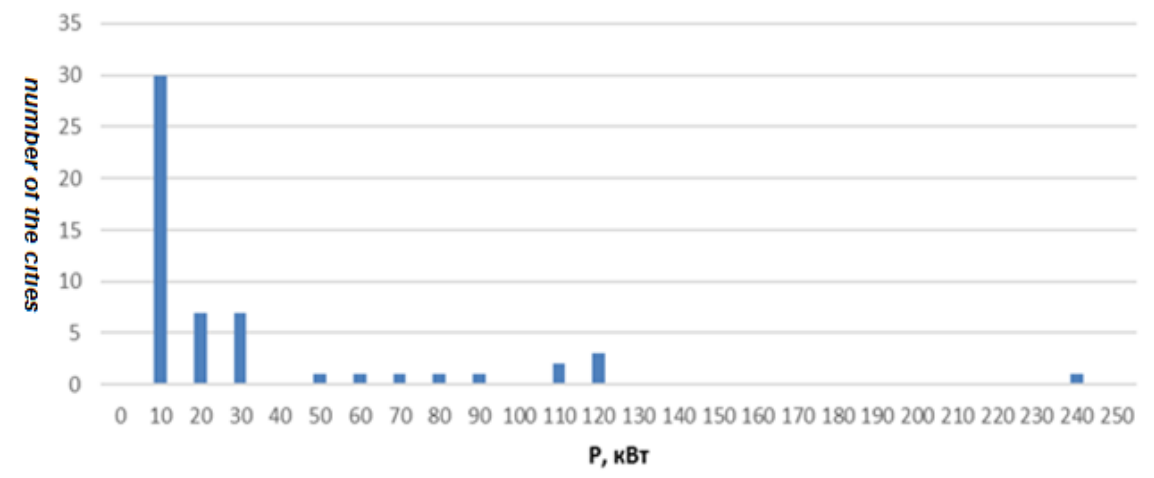

Fig. 5. The histogram for distribution of power wind turbines by cities of Republic of Tajikistan.

In addition to this, an assessment of solar energy potential was conducted, namely the clarity of days in the year. The daily solar radiation in the form of radiation $\mathrm{kWh} / \mathrm{m}^{2}$ per day. The average capacity by cities is from 1300 to $1600 \mathrm{~kW}$ per solar plant area of $1000 \mathrm{~m}^{2}$. The mathematical expectation is $1400 \mathrm{~kW}$. Figure 6 shows the distribution of solar power sources.

Installation of helio megawatt-class solar plants is considered. Per their capacity and classification of renewable energy plants, they belong to the class of mini power plants defined by the function of belonging according to the formula (3). Thus, the solar potential of the Republic of Tajikistan is considerably higher than wind power.

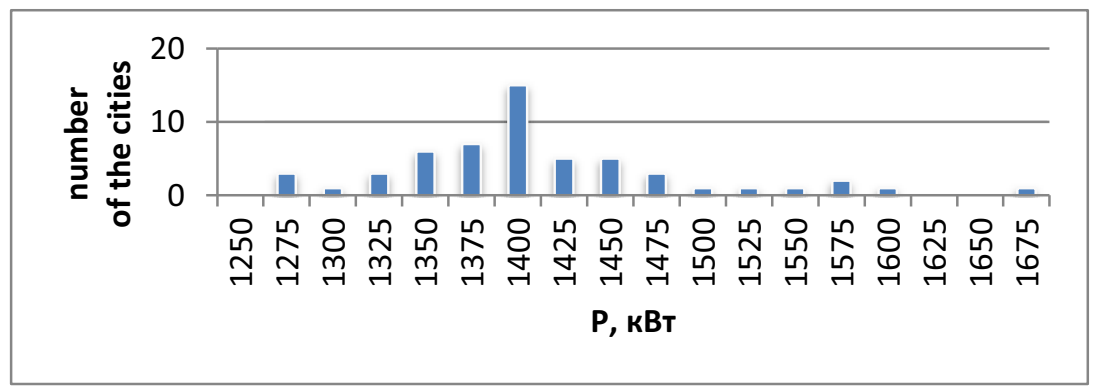

Fig. 6. Histogram of distribution of power of solar energy in the Republic of Tajikistan. 
In the context of the power centers, the whole infrastructure of power supply it can be considered as system of the related power centers. In Figure 3 communication of three power centers is presented which includes integration of electric and thermal networks. It is an example for power supply of settlements and cities, which approximately divided into three areas: industrial enterprises, commercial spheres, and private houses.

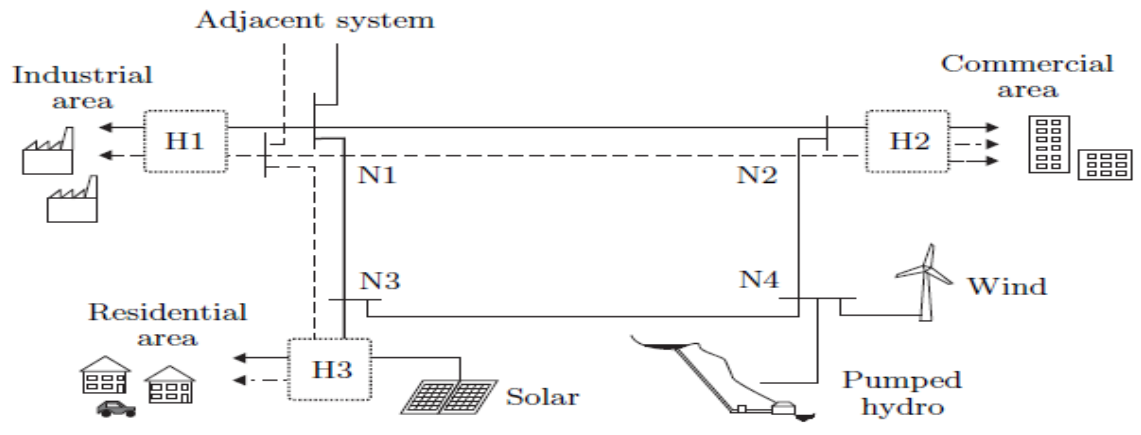

Fig. 7. Systems of related power centers.

Each area connects to distribution electric networks and thermal sources through the power centers. The internal arrangement of the centers is adapted for certain requirements of electric and thermal consumers. Power is transmitted through adjacent networks, photovoltaic sources, connected to H3 center, and wind-powered turbines and hydroelectric power stations are connected to an electric network through the N4 hub [1,2]. This network can represent more remote hydroelectric power station near settlements and the cities where there are reservoirs for accumulation of energy of water or accumulators of energy of other type of BESS.

Transmission of energy between centers in the combined system for different types of energy carriers in the distributed system has to possess static stability that is subject to additional research [3]. Autonomous management of renewable energy sources, especially wind turbines, considered in $[4,5]$ are subject to further discussion.

\section{Conclusion}

The principles of creation of HUB offered in this work represents composition of distributed renewable sources of "net energy" of different types, such as small hydroelectric power stations, winder-powered turbines and low-powered wind stations, solar batteries and static stores of energy (BESS - Battery Energy Storage System). This is what is the fundamental difference of the offered HUB in the Republic of Tajikistan. The uniqueness of this HUB is in combined modes of operation of hydro, wind and solar resources in the simultaneous mode of competition with eacho the rand also complement each other Uniqueness of this HUB is reflected in a combined operating modes of water resources, wind and solar resources in the modes of the simultaneous competition among themselves and complementarity to each other. This way, electric HUB of the Republic of Tajikistan will work with the 100 percentage generation of a net energy of all types of renewable sources. Perhaps, it will be unique HUB in world power. 


\section{References}

1. Z. Yuldashev, R. Yuldashev et al., Bulletin of the Tajik technical university, 2 (26). 59-61 (Dushanbe, 2014).

2. S. Rasulov, A. Kirgizov, and U. Kasymov, Power: Ecology, Reliability, Safety: materials of the eighteenth All-Russian scientific and technical conference. 99-101 (Tomsk, 2012).

3. M. Geidl, and G. Andersson, IEEE Transactions on Power Systems, Vol. 22, 1, 145-155 (February 2007).

4. V.Z. Manusov, S.N. Udalov, Modeling of wind power installations and management of them on the basis of fuzzy logic: monograph (Novosibirsk, 2013).

5. V.Z. Manusov, S.K. Khaldarov, Applied Mechanics and Materials. Vol. 698: Electrical Engineering, Energy, Mechanical Engineering, EEM 2014, www.scientific.net/AMM.698.168 